JURNAL PENDIDIKAN USIA DINI

DOI: https://doi.org/10.21009/JPUD.121
DOI: https://doi.org/10.21009/JPUD.121 06

\title{
HUBUNGAN KERJASAMA ORANGTUA DENGAN PERKEMBANGAN ANAK USIA DINI DI KELOMPOK BERMAIN
}

\author{
ISLAMIYATI \\ Poltekkes Tanjungkarang Prodi Kebidanan Metro \\ Jl. Brigjend Sutiyoso No. 1 Kota Metro Lampung \\ Email: islamiyati_sadiman@yahoo.com
}

\begin{abstract}
ABSTRAK
The study aims to determine the relationship of parents cooperation with the development of early childhood in playgroup in the working area of Metro Health Center. This study used an analytic cross sectional method. The samples are all of the member of play group in 9 playgroups in working area of Metro Health Center with 147 children. The data collection used is questionnaire and the filling methods are in the form of checklist and observation. This studies are conducted in May June 2015. The data analysis used is chi square analysis. The result study shows that $50 \%$ of children development are suitable with his growth and development. Most of parents cooperation are still not good. The correlation between parents cooperation with child development will help the children development optimally. It is suggested thsat the teacher of the school to improve the cooperation with the parents.
\end{abstract}

Keywords: Play group, cooperation of parents, development, early childhood

Penelitian ini bertujuan untuk mengetahui hubungan kerjasama orang tua dengan perkembangan anak usia dini di Kober wilayah kerja Puskesmas Metro. Metode penelitian yang digunakan analytic cross sectional. Sampel sebanyak 147 orang berasal dari 9 Kober di wilayah kerja Puskesmas Metro. Pengumpulan data menggunakan kuesioner dan cara pengisian dalam bentuk checklist dan observasi. Penelitian dilaksanakan pada Bulan Mei - Juni 2015. Analisa data menggunakan analisis chi square. Hasil penelitian diperoleh informasi $50 \%$ perkembangan anak sesuai dengan tumbuh kembang. Kerjasama orang tua sebagian besar kurang baik. Kerjasama orang tua dengan pihak Kober dapat membantu perkembangan anak yang optimal. Disarankan pihak sekolah meningkatkan kerjasama dengan orang tua.

Kata Kunci: Kober, kerjasama orang tua, perkembangan, anak usia dini 


\section{PENDAHULUAN}

Usia dini selain dikenal sebagai masa keemasan (the golden age), namun juga merupakan masa yang sangat kritis (critical period) dan jendela kesempatan (window of opportunity) dalam tahap perkembangan anak. Hasil penelitian mengungkapkan tingkat kapabilitas kecerdasan anak mencapai 50\% sampai anak berusia 4 tahun. Mencapai $80 \%$ pada usia 8 tahun dan sisanya $20 \%$ dicapai anak ketika berusia 8 tahun ke atas. Derajat kualitas kesehatan, intelegensi, kematangan emosional, dan produktifitas manusia sangat ditentukan oleh pertumbuhan dan perkembangan anak pada usia dini (Kemendiknas, 2011:1; Kemenkes, 2012:1). Kondisi ini yang pada akhirnya akan dapat menyiapkan generasi yang sehat dan berkualitas dalam membangun bangsa.

Anak usia dini (AUD) merupakan bagian dari balita yang jumlahnya sekitar $10 \%$ dari populasi merupakan generasi penerus bangsa, perlu perhatian khusus pada aspek kesehatan dengan mendapat gizi seimbang sesuai usia, stimulus yang sesuai usia serta mendapat pelayanan kesehatan berkualitas termasuk deteksi dan intervensi dini penyimpangan baik pertumbuhan maupun perkembangan sehingga tumbuh kembang anak dapat tumbuh secara optimal sesuai dengan usianya serta potensi yang dimiliki anak sehingga anak mampu menyiapkan diri untuk kemajuannya di masa yang akan datang (Kemenkes RI, 2012:1).

Kualitas tumbuh kembang akan menentukan kualitas anak secara keseluruhan, sehingga dibutuhkan deteksi dini tumbuh kembang yang sesuai dengan usia anak, terutama pada anak yang berusia 0-5 tahun. Peran keluarga terutama orang tua sangat besar dalam mengupayakan agar anaknya tumbuh kembang optimal. Penyimpangan tumbuh kembang harus dideteksi (diketahui) sejak awal, terutama anak di bawah usia 3 tahun. Deteksi yang terlambat menyebabkan penanganan yang terlambat sehingga penyimpangan sukar diperbaiki (Maulidaniah S, 2011).

Pendidikan AUD bukan hanya tanggung jawab guru, tapi juga orang 
Hubungan Kerjasama Orangtua.... Islamiyati

tua, masyarakat dan negara. Setiap orang tua mempunyai cara mendidik anak yang berbeda dan setiap orang tua menginginkan adanya partner dalam mendidik anak. Biasanya orang tua akan memasukkan anaknya ke sekolah dalam rangka mencari partner dalam mendidik anak yaitu guru. Orang tua selalu berharap ada kerja sama antara mereka dengan guru sehingga anak-anak mereka dapat berhasil dan sukses. Tapi sebagian orang tua menganggap bahwa jika anaknya sudah dimasukkan ke salah satu sekolah, maka anak utuh menjadi tanggung jawab guru sehingga mereka melalaikan tanggung jawab mereka terhadap pendidikan anak yang menyebabkan hambatan dalam perkembangan terutama psikologis anak ((Setiawan dan Lidia, 2016).

\section{KAJIAN TEORITIK}

\section{Kerjasama Orang Tua dengan Guru}

Pendidikan merupakan tanggung jawab bersama antara sekolah, masyarakat dan keluarga (dalam hal ini adalah orang tua). Orang tua akan mencarikan partner dalam mendidik anaknya agar anak mencapai prestasi dan tumbuh kembang secara optimal yaitu sekolah yang dalam hal ini anak akan dididik oleh guru. Orang tua yang baik tidak selayaknya menyerahkan tanggung jawab pendidikan anak hanya dengan memasukkan anak-anaknya ke suatu sekolah tanpa ikut aktif dalam kegiatan yang dilaksanakan oleh sekolah tersebut.

$$
\text { Ada beberapa bentuk }
$$

kerjasama antara orang tua dan guru dalam rangka mencetak anak-anak menjadi generasi yang sehat, cerdas dan bertumbuh kembang sesuai usianya, yaitu:

a. Konferensi orang tua (Case

\section{Conference)}

Dilakukan jika ada permasalahan terhadap anak didik. Konferensi ini dipimpin oleh orang yang paling mengetahui permasalahan anak yang bertujuan untuk mencari jalan yang paling tepat dalam menyelesaikan permasalahan anak didik

b. Pertemuan dengan orangtua secara pribadi

Kesalahpahaman antara orang tua dan guru tidak akan terjadi jika ada pertemuan guru dan orang tua 
Hubungan Kerjasama Orangtua.... Islamiyati

secara pribadi, dimana pertemuan tersebut sangat efektif dilakukan jika murid mempunyai permasalahan yang harus diselesaikan dan melibatkan orang tua.

c. Kunjungan guru ke rumah orangtua murid (home visit), atau sebaliknya kunjungan orangtua murid ke sekolah

Kunjungan guru ke rumah anak didik sangatlah penting dengan tujuan untuk menciptakan perasaan bagi anak bahwa sekolah selalu memperhatikannya baik di sekolah maupun di rumah. Kunjungan ke rumah oleh guru juga dapat menciptakan komunikasi dengan orang tua dan dapat menyampaikan segala sesuatu yang terkait anak tersebut kepada orang tua. Sebaliknya kunjungan orang tua murid ke sekolah atau orang tua yang diundang ke sekolah sangat baik agar orang tua dapat melihat dan mengetahui berbagai kegiatan anaknya di sekolah dan juga dapat membantu perkembangan anak didik. d. Mengadakan surat menyurat antara sekolah dan keluarga

Surat menyurat dibutuhkan terutama jika ada sesuatu pemberitahuan dari pihak sekolah kepada orang tua. Selain itu surat menyurat juga dapat dilakukan untuk anak mempunyai permasalahan yang harus diketahui oleh orang tua, sehingga orang tua dapat ikut dalam penyelesaian masalah anaknya

e. Mengadakan perayaan, pesta sekolah atau pameran-pameran hasil karya murid

Hal ini akan sangat bermanfaat agar para orang tua dapat melihat hasil karya anak mereka selama mereka sekolah dan dapat memberikan pujian dan motivasi kepada anakanak mereka

f. Mendirikan perkumpulan orang tua dan guru.

Tujuannya untuk mempermudah kerja sama antara guru dengan orang tua. Semakin sering dilakukan pertemuan antara guru dan orang tua akan semakin erat hubungan kerja sama antara keduanya sehingga dapat 
Hubungan Kerjasama Orangtua.... Islamiyati

mengoptimalkan perkembangan anak.

g. Adanya Daftar Nilai atau Raport Daftar nilai atau raport adalah hasil laporan kemajuan perkembangan pendidikan anak dan merupakan penghubung antara orang tua dan guru terutama bagi orang tua yang sibuk dan jarang bisa berkomunikasi dengan pihak sekolah. Dari raport ini orang tua dapat mengetahui kemajuan pendidikan anaknya walau mereka tidak dapat melihat setiap harinya.

Berikut disampaikan kerangka teori dalam penelitian ini.
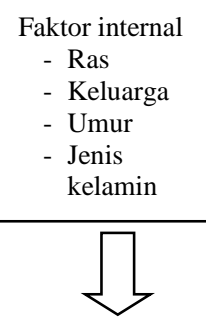

Balita dan Anak Prasekolah

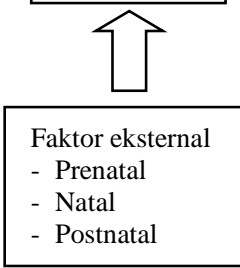

- Natal

- Postnatal

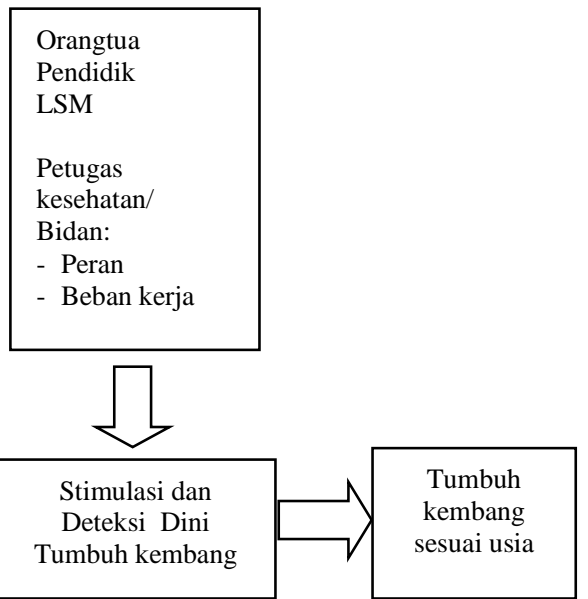
Tumbuh kembang

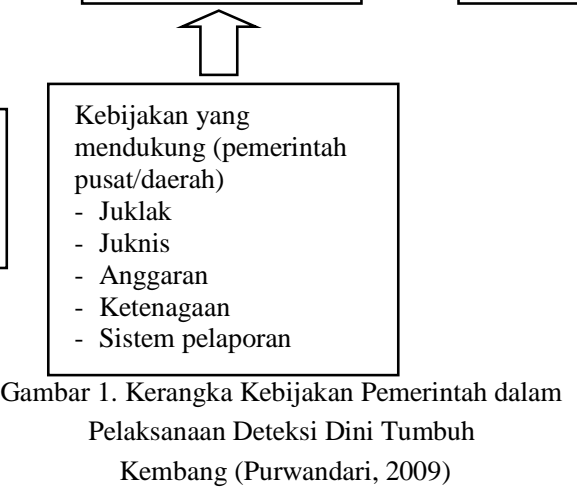

\section{METODE PENELITIAN}

Metode penelitian yang digunakan analitik cross sectional. Metode ini dipilih karena dalam penelitian ini pengumpulan data baik faktor resiko maupun efek dilakukan dalam waktu yang bersamaan. Sampel sebanyak 147 orang yang berasal dari kober wilayah kerja Puskesmas Metro. Peneliti melakukan penilaian perkembangan anak dengan KPSP kemudian memberikan kuisioner kepada orang tua mengenai kerjasama orang tua dengan pihak pendidikan kelompok Bermain (Kober). Instrumen dalam penelitian ini adalah kuisioner dan cara pengisian dalam bentuk checklist dan observasi. Penelitian dilaksanakan pada Bulan Mei - Juni 2015. Data dianalisis menggunakan analisis chi square. Analisis ini dipilih karena baik variabel dependen maupun independen berskala kategorik.

\section{HASIL DAN PEMBAHASAN}

\section{Hasil Penelitian}

\section{Perkembangan Anak}

Perkembangan anak usia dini di Kober wilayah kerja Puskesmas Metro sebagian besar $(50,3 \%)$ sesuai dengan 
Hubungan Kerjasama Orangtua.... Islamiyati

usia anak, dan dapat dilihat pada diagram berikut ini:

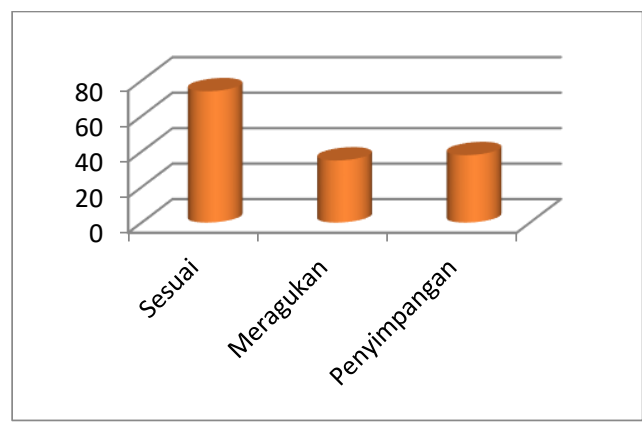

Gambar 1. Perkembangan Anak Usia Dini di Kelompok Bermain

Berdasarkan gambar di atas diketahui bahwa 74 orang $(50,3 \%)$ anak dengan perkembangan sesuai usia, 35 orang $(23,8 \%)$ anak dengan perkembangan meragukan dan 38 orang $(25,9 \%)$ anak dengan perkembangan penyimpangan.

\section{Kerjasama Orang tua}

Kerjasama orang tua anak usia dini dengan pihak institusi di Kober wilayah kerja Puskesmas Metro sebagian besar kurang baik $(38,1 \%)$, seperti terlihat pada diagram berikut ini:

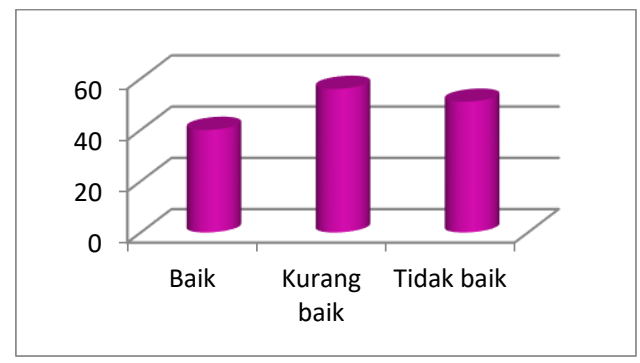

Gambar 2. Kerjasama Orang Tua di kelompok Bermain
Berdasarkan gambar di atas diketahui bahwa 40 orang tua $(27,2 \%)$ dengan kerja sama baik, 56 orang tua $(38,1 \%)$ dengan kerja sama kurang baik dan 51 orang tua $(34,7 \%)$ dengan kerja sama tidak baik.

\section{Hubungan Pekembangan Anak dengan Kerjasama Orang tua}

Berdasarkan analisis yang dilakukan dengan Chi Square didapatkan p value sebesar 0,000 yang berarti terdapat hubungan antara kerjasama orang tua dengan perkembangan anak usia dini di Kober wilayah kerja Puskesmas Metro. Didapatkan hasil sebagian besar anak dengan kerjasama orang tua yang baik akan menghasilkan perkembangan yang sesuai sedangkan sebagian besar anak dengan kerjasama orang tua yang tidak baik menghasilkan perkembangan yang menyimpang.

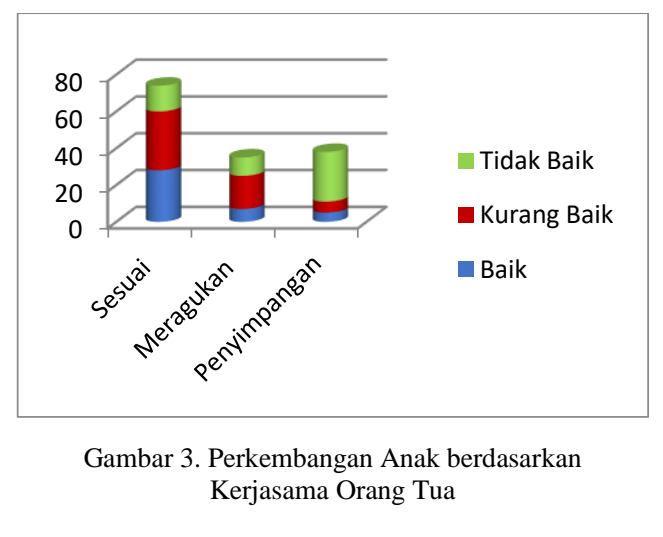


Hubungan Kerjasama Orangtua.... Islamiyati

Berdasarkan gambar diketahui bahwa anak dengan perkembangan yang sesuai $38 \%$ kerja sama orang tuanya baik, $43 \%$ kerja sama orang tuanya kurang baik dan 19\% kerja sama orang tuanya tidak baik. Anak dengan perkembangan yang meragukan $20 \%$ kerja sama orang tuanya baik, $51 \%$ kerja sama orang tuanya kurang baik dan $29 \%$ kerja sama orang tuanya tidak baik. Anak dengan perkembangan penyimpangan $13 \%$ kerja sama orang tuanya baik, 16\% kerja sama orang tuanya kurang baik dan $71 \%$ kerja sama orang tuanya tidak baik.

\section{Pembahasan}

\section{Perkembangan Anak}

Berdasarkan hasil penelitian diketahui bahwa lebih dari separuh $(50,3 \%)$ perkembangan anak usia dini di kober wilayah kerja Puskesmas Metro adalah sesuai dengan usia anak. Hasil penelitian ini masih di bawah penelitian di PAUD Kartika Desa Gumukrejo Kecamatan Pagelaran Kabupaten Tanggamus Lampung Tahun 2009 yang mendapatkan bahwa dari 30 orang siswa PAUD terdapat
93.3\% perkembangan yang sesuai dengan usia.

Hasil ini juga lebih rendah jika dibandingkan penelitian di TK Masyitoh V Desa Margasari Kabupaten Tegal tahun 2013 yang mendapatkan $85,7 \%$ anak dengan perkembangan yang sesuai (Anggraeni, dkk, 2014).

Perkembangan anak yang baik adalah sesuai dengan usia anak. Jika anak sering distimulasi maka perkembangan akan sesuai dengan usianya dan anak dapat mengikuti kegiatan anak seusianya.

Pada penelitian ini masih ditemukan perkembangan anak yang meragukan sebanyak $23.8 \%$ dan penyimpangan sebanyak $25.9 \%$. Hasil ini dimungkinkan karena kurangnya stimulasi dari orang tua, dimana orang tua sebagian besar menyerahkan perkembangan anaknya pada pihak sekolah. Agar perkembangan anak optimal sesuai dengan usianya sebaiknya orang banyak melakukan stimulasi terhadap anaknya dengan berkolaborasi pada pihak kober.

\section{Kerjasama Orang tua}

Penelitian ini memperoleh hasil sebagian besar $(38,1 \%)$ orang tua 
Hubungan Kerjasama Orangtua.... Islamiyati

anak usia dini di kober wilayah kerja Puskesmas Metro adalah tidak baik. Kerjasama antara orang tua dengan guru Kober sebagian besar tidak baik, hal ini terlihat dari jarangnya pertemuan antara orang tua dengan guru, sehingga jarang sekali ada komunikasi langsung antara keduanya. Penelitian ini juga mendapatkan bahwa sebagian besar $(33,3 \%)$ orang tua mengatakan kadang-kadang menghadiri pertemuan dari sekolah bahkan sebanyak 35\% tidak menjawab pertanyaan yang diberikan. Sebagian besar orang tua adalah orang yang sibuk bekerja baik sebagai pegawai di instansi pemerintah maupun swasta. Anak hanya diantar jemput oleh pengasuh, kakek/nenek, bahkan ada yang diantar jemput oleh abodemen.

Kurangnya kerjasama antara orang tua dan guru kober akan sangat mempengaruhi perkembangan anakanak kober. Dengan kurangnya komunikasi antara guru dan orang tua dapat mengakibatkan tujuan pembelajaran tidak tercapai secara optimal. Hubungan dan kerja sama yang baik antara guru dan orang tua maka akan dapat mengembangkan seluruh aspek-aspek perkembangan anak. Orang tua membutuhkan gambaran bagaimana kondisi anaknya ketika sekolah dan guru juga membutuhkan informasi dari orang tua bagaimana karakteristik anak yang sesungguhnya sehingga pendidikan anak dapat dioptimalkan sesuai dengan karakteristik masing-masing. Kerja sama yang baik ini mendukung teori kolaborasi Situated Cognitive dimana kerja sama yang baik antara orang tua dan guru akan mendukung motivasi dan kreativitas anak sehingga anak akan dapat berkembnag sesuai usianya (Aditya WP, 2016)

\section{Hubungan Pekembangan Anak dengan Kerjasama Orang tua}

Berdasarkan hasil penelitian didapatkan bahwa ada hubungan kerja sama orang tua dengan perkembangan anak usia dini di Kober wilayah kerja Puskesmas Metro.

Kita ketahui bahwa pendidikan itu bukan hanya tanggung jawab guru tapi juga merupakan tanggung jawab bersama antara orang tua, guru, masyarakat dan pemerintah. Pendidikan anak tidak akan berhasil optimal jika ada salah satu unsur yang 
Hubungan Kerjasama Orangtua.... Islamiyati

tidak terlibat dalam proses tersebut. Pendidikan pertama dan paling utama adalah dari keluarga yang dalam hal ini dimotori oleh orang tua. Selanjutnya sekolah yang di dalamnya terlibat para guru akan melanjutkan pendidikan yang didapat anak di rumah.

Sikap anak-anak selama sekolah akan dipengaruhi oleh sikap orang tuanya. Selain itu diperlukan juga kepercayaan orang tua terhadap sekolah agar terjalin hubungan yang harmonis antar keduanya. Dengan adanya kerja sama yang baik dan harmonis antara orang tua dan guru banyak kekurangan anak yang dapat diatasi. Kekurangan anak yang tidak dapat diatasi orang tua di rumah mungkin dapat dicarikan solusi oleh guru di sekolah, demikian juga sebaliknya kekurang anak yang tidak dapat diselesaikan di sekolah mungkin dapat dicarikan solusinya oleh orang tua di rumah.

Kerja sama antara guru dan orang tua sangatlah penting karena kedua pihak inilah yang setiap hari selalu berinteraksi dengan anak. Jika kerja sama antara orang tua dan guru kurang bahkan tidak baik jangan berharap akan menghasilkan pendidikan dan perkembangan anak yang baik (Setiawan dan Lidia, 2016).

Berbagai bentuk kerja sama antara orang tua dan guru dapat dilakukan untuk mencapai keberhasilan pendidikan anak diantaranya mulai dari konferensi (pertemuan bersama) orang tua, pertemuan orang tua dan guru secara pribadi, kunjungan baik oleh orang tua ke sekolah maupun kunjungan guru ke rumah (home visit), surat menyurat dari sekolah ke keluarga atau sebaliknya, acara/perayaan di sekolah yang menampilkan karya murid serta perkumpulan orang tua. Kegiatankegiatan tersebut dapat meningkatkan interaksi antara guru dan orang tua yang nantinya diharapakan dapat memacu perkembangan anak agar lebih baik.

Kerja sama orang tua kober dan pihak kober di wilayah kerja Puskesmas Metro sebagian besar tidak baik. Pernyataan ini dapat dilihat dari pertanyaan yang diajukan peneliti kepada orang tua yang mendapatkan bahwa sebagian besar orang tua hanya kadang-kadang menghadiri pertemuan yang dilakukan oleh sekolah dengan 
Hubungan Kerjasama Orangtua.... Islamiyati

alasan karena kesibukan orang tua, merasa hal tersebut tidak penting. Berdasarkan hasil penelitian ini juga mendapatkan data bahwa tidak ada orang tua yang ikut/hadir dalam kegiatan deteksi dini tumbuh kembang anak yang dilakukan oleh petugas kesehatan di PAUD dengan alasan tidak ada waktu, tidak ada pemberitahuan dari pihak sekolah bahkan sebagian merasa hal tersebut tidak penting. Hasil penelitian ini mendukung teori bahwa orang tua sebagian beranggapan bahwa jika anaknya sudah dimasukkan ke sekolah maka tugas pendidikan dan perkembangan anak menjadi tanggung jawab guru, sehingga orang tua melalaikan tugasnya dalam mendidik dan menstimulasi anaknya (Setiawan dan Lidia, 2016).

\section{KESIMPULAN}

Simpulan dari penelitian ini ada hubungan antara kerjasama orang tua dengan pihak kober terhadap perkembangan anak usia dini di kober wilayah kerja Puskesmas Metro. Saran kepada pihak Kober agar dapat menjalin kerjasama yang baik dengan pihak orang tua dengan berbagai cara/metode agar tercipta perkembangan yang optimal sesuai dengan usia anak.

\section{DAFTAR PUSTAKA}

Aditya WP, (2016), Kajian Teori Kerja Sama Guru dan Orang Tua dalam Pendidikan Anak, http://dunia-belajar.blogspot.co.id.

Anggraeni I.E, Masturoh, Naharani A.R, (2014). Hubungan Tingkat Pengetahuan Ibu tentang Stimulasi Perkembangan Anak dengan Perkembangan Anak Usia 48-60 Bulan di TK Masyitoh Desa Margasari Kecamatan Margasari Kabupaten Tegal, Bhamada, JITK, Vol. 5, No. 2, November 2014.

Arliani S, dkk, (2012), Hubungan Stimulasi Orang Tua Dengan Perkembangan Anak Usia 1-3 Tahun di Desa Kampil Kecamatan Wiradesa Kabupaten Pekalongan, Prodi S1 Keperawatan STIKES Muhammadiyah Pekajangan Pekalongan

Irmawati, (2007). Analisis Hubungan Fungsi Manajemen Pelaksana Kegiatan Stimulasi Deteksi dan Intervensi Dini Tumbuh Kembang (SDIDTK) dengan Cakupan SDIDTK Balita dan Anak Pra Sekolah di Puskesmas Kota Semarang Tahun 2006 (Tesis), UNDIP, Semarang. Semarang.

Kemendiknas, (2011), Petunjuk Teknis Penyelenggaraan Kelompok Bermain, Direktorat 
Hubungan Kerjasama Orangtua.... Islamiyati

Jenderal Pendidikan Anak Usia Dini, Non Formal dan Informal, Jakarta

(2009), Permendiknas

No. 58 Tahun 2009 tentang

Standar Pendidikan Anak Usia Dini, Jakarta

Kemenkes RI, (2012), Instrumen Stimulasi, Deteksi Dini dan Intervensi Dini Tumbuh Kembang Anak, Dirjen Bina Kesmas, Jakarta

(2012). Pedoman Pelaksanaan Stimulasi, Deteksi Dini dan Intervensi Dini Tumbuh Kembang Anak di Tingkat Pelayanan Kesehatan Dasar, Dirjen Bina Kesmas, Jakarta

Deteksi Dan Intervensi Dini Tumbuh Kembang (SDIDTK)Anak, https://infobidannia.wordpress.co $\mathrm{m} / 2011 / 06 / 0$ stimulasi-deteksidan-intervensi-dini-tumbuhkembang-sdidtk-anak

Purwandari H, (2009). Kebijakan Pemerintah dalam Pelaksanaan Deteksi Dini Tumbuh Kembang (Tesis), Universitas Sebelas Maret, Surakarta

Setiawan HR dan Lidia, (2016), Kerjasama Guru dan Orang Tua dalam Pendidikan Anak, Harian Jurnal Asia, Medan, 3 Agustus 2016

Sididitk.com, 2014, KPSP untuk Anak Sesuai Umur, kpsp_SiDiDiTK.htm, diakses 10 Oktober 2014Soetjiningsih. Skrining Perkembangan dalam
Upaya Deteksi Dini dan Meningkatkan Kualitas Hidup Anak dalam Tumbuh Kembang, Nutrisi dan Endokrin, SMF Ilmu Kesehatan Anak FK Ulam/RSUD Ulin.

Soetjiningsih, (2015), Tumbuh Kembang Anak, EGC, Jakarta.

Subardiah I dan Setiawati, (2014), Panduan Pemeriksaan Perkembangan Denver II dan KPSP, Maternity and Child Care Centre, Bandar Lampung.

Susanti N, dkk, (2014), Deteksi Dini Masalah Perkembangan Anak Taman Kanak-kanak dengan Menggunakan KPSP, Universitas Pendidikan Indonesia, Jakarta

Utina J, dkk, (2012), Hubungan Antara Status Bekerja Ibu Dengan Pencapaian Tumbuh Kembang Anak Usia Batita Di Kelurahan Maasing Kecamatan Tuminting Kota Manado, Jurusan Keperawatan Poltekkes Kemenkes Manado, Juiperdo, Vol 1 No. 1 Maret 2012 